\title{
Hydrophobicity of myxomycete spores: An undescribed aspect of spore ornamentation
}

\section{Hoppe $T^{1}$ and Schwippert $\mathrm{WW}^{2}$}

\author{
${ }^{1}$ Institute of Botany and Landscape Ecology, University of Greifswald, Soldmann-Street 15, D-17487 Greifswald, \\ Germany \\ ${ }^{2}$ Department of Neurobiology, University of Kassel, Heinrich-Plett-Street 40, D-34131 Kassel, Germany
}

Hoppe T, Schwippert WW 2014 - Hydrophobicity of myxomycete spores: An undescribed aspect of spore ornamentation. Mycosphere 5(4), 601-606, Doi 10.5943/mycosphere/5/4/12

\begin{abstract}
Plasmodial slime molds are adapted to a number of different ecosystems. Spores could be classified into three different ornamentation types: spiny, reticulate and smooth surfaces. We examined three different hydrophobic effects for these surface types. The surface energy was calculated for Metatrichia floriformis (reticulate) $=25.61 \mathrm{~J}$, Fuligo septica var. candida $($ spiny) $=$ $50.81 \mathrm{~J}$, Ceratiomyxa fruticulosa $($ smooth) $=72.63 \mathrm{~J}$ and Licea parasitica (smooth) $=72.74 \mathrm{~J}$. Spores with spines half-sink into the water surface. However, they float on the surface. Reticulate spores show super-hydrophobic effects and are refractive to the water surface. Spores without ornamentation sink after contact with water.
\end{abstract}

Key words - dispersal strategies - spore morphology - surface-energy

\section{Introduction}

Myxomycetes are common protoctista of natural habitats. There are two possible strategies to colonize a new habitat. We differentiate an active (via amoeba or plasmodia) and a passive (dispersal by spores and cysts) form of disperse. The life cycle can be described as a two generation model (Fig. 1). Firstly, it is possible to divide the cells into a haploid and a diploid stage. The relatively huge diploid plasmodium produces one or more fruiting bodies (sporocarps). Within these structures haploid spores are formed. According to the actual literature, within this phase meiotic divisions of the nucleolus take place. Four haploid pre-nucleoli are enclosed in one spore, three of these prenucleoli degenerate. At the end of the process haploid spores are produced (Fig.1a). These are dispersed by wind. For spore germination, a humid environment is needed (Bruck 1907). The swarm cells (myxamoebae in Fig. 1b) divide via mitosis. There are different models for colonization of a new habitat. Locomotion is possible for amoebae or plasmodia (1c). Another model is zoochory of spores, amoebae and microcysts (1e) (Müller 2006). Spores and cysts primarily disperse by wind for long distances (Stephenson et al. 2008). Autochory appears more effective for species with low spore diameter (Tesmer \& Schnittler 2008). Anyways a successful colonization needs humidity for germination of the spores/cysts. We examined the effect of water after the first contact of a spore. The spores of the myxomycetes can be distinguished in three different types: smooth, with spines, with a reticulate surface. The functions of these structures were unclear up to now. We examined 17 species belonging to these different spore types for difference in activity. 


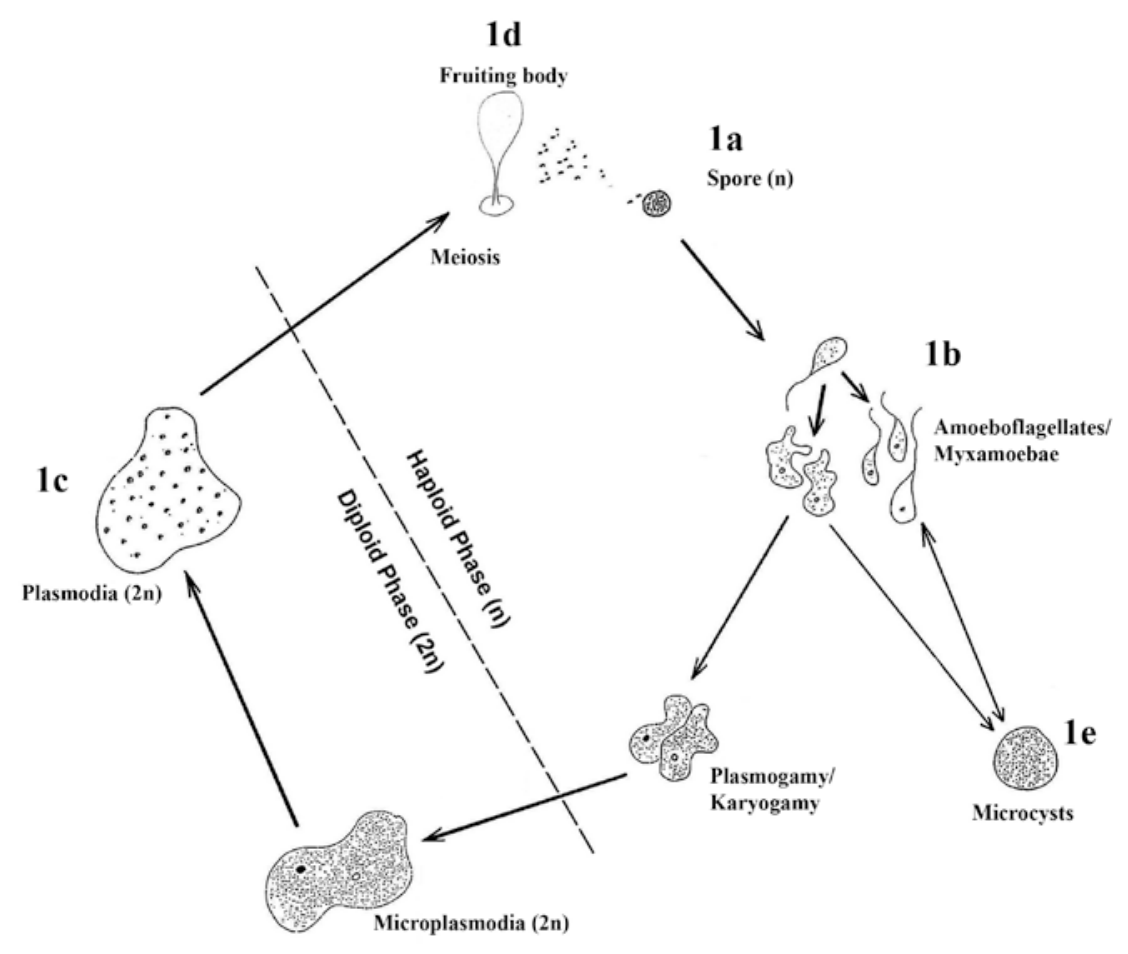

Fig. 1 - The life cycle of a typical myxomycete. Spores (1a) are formed, after germination develop swarm cells (1b). Dormant stages, like microcysts (1e) are formed when the organisms are resting. Two haploid cells merge generating a diploid microplasmodia. This cell grows forming a plasmodia (1c) and subsequent forms a fruiting body (1d).

\section{Materials \& Methods}

Spores of morphologically different species were used (collection of T. Hoppe, Ernst-MoritzArndt University Greifswald, Germany). For SEM analysis, the spores were prepared as described in Hoppe \& Kutschera (2010). For deletion of surface proteins formic acid (20\%) was added to the spores at different time (10/ 20/ $60 \mathrm{~min})$. The acid was washed out using $\mathrm{ddH}_{2} \mathrm{O}$ and a hydrophobic effect was observed. The surface of 17 species was observed by SEM. The contact angle and dimensions of the spore surface were determined according to Kwon et al. (2009) (Figs. 2a, b).

a

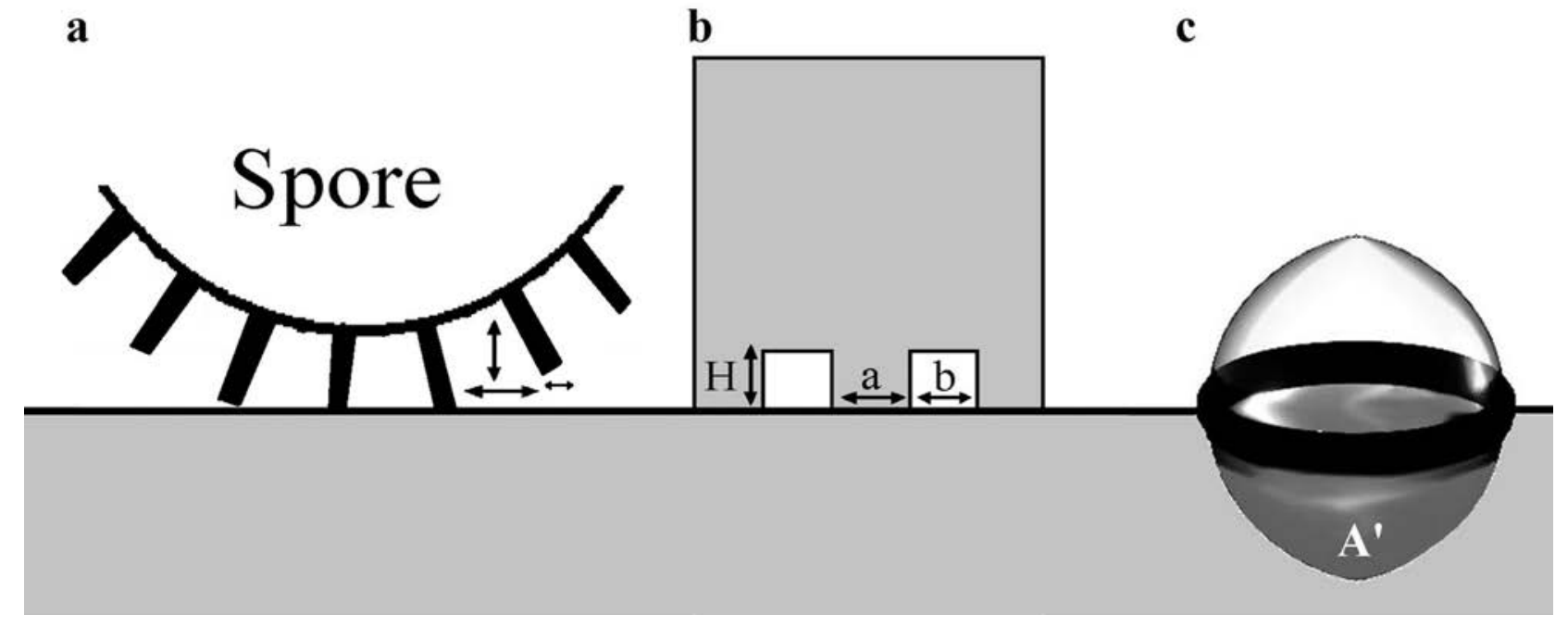

Fig. 2 - The hydrophobic effect: (a) spore with spines, (b) draft of the measured parameters, (c) contact area of the spore and water. 
For calculation of the hydrophobic effect spores of 17 species were photographed on the water surface. We calculated the characters of surface-structures according to Kwon et al. (2009) and determined the contact angle $\theta^{\mathrm{w}}{ }_{\mathrm{r}}$. The fraction area $(\boldsymbol{W})$ is described as the relation of the roughened area to the projected area and $\theta_{\mathrm{i}}$ is the intrinsic contact angle. This area fraction could be described by $\boldsymbol{W}=1+4 C /(\boldsymbol{a} / \boldsymbol{H})$. We also calculated the area fraction of liquid-solid $\boldsymbol{C}$ with the formula $\boldsymbol{C}=\mathbf{1} /(\boldsymbol{b} / \boldsymbol{a}+\mathbf{1})^{2}$, wherein $\boldsymbol{a}$ is the diameter of the spine, $\boldsymbol{b}$ is the distance between two spines and $\boldsymbol{H}$ is the height of the spine.

The contact area (A') of the spore and water was calculated (Fig. 2c) and with these results we determined the surface energy for Fuligo septica var. candida (spine), Metatrichia floriformis (reticulate), Ceratiomyxa fruticulosa and Licea parasitica (smooth type) according to Young (1805) and Noblin et al. (2009).

\section{Results}

When the surface energy $\sigma \mathrm{S}$ of the spore is low, then the surface is more hydrophobic. With a contact angle near to $0^{\circ}$ to the surface, the structure is hydrophilic. A contact angle around $90^{\circ}$ to the surface on the other hand, results in hydrophobic behavior. A contact angle of ca. $160^{\circ}$ could be called super hydrophobic. The contact angles are $63^{\circ}\left( \pm 10.9^{\circ}\right)$ for reticulate spores and $116^{\circ}( \pm$ $2.35^{\circ}$ ) for spiny spores (Fig. 2, Tab. 2). The energy $\sigma$ LS of Metatrichia floriformis (reticulate) $=$ $25.61 \mathrm{~J}$, Fuligo septica var. candida (spiny) $=50.81 \mathrm{~J}$ and Ceratiomyxa fruticulosa (smooth) $=$ $72.63 \mathrm{~J}$.

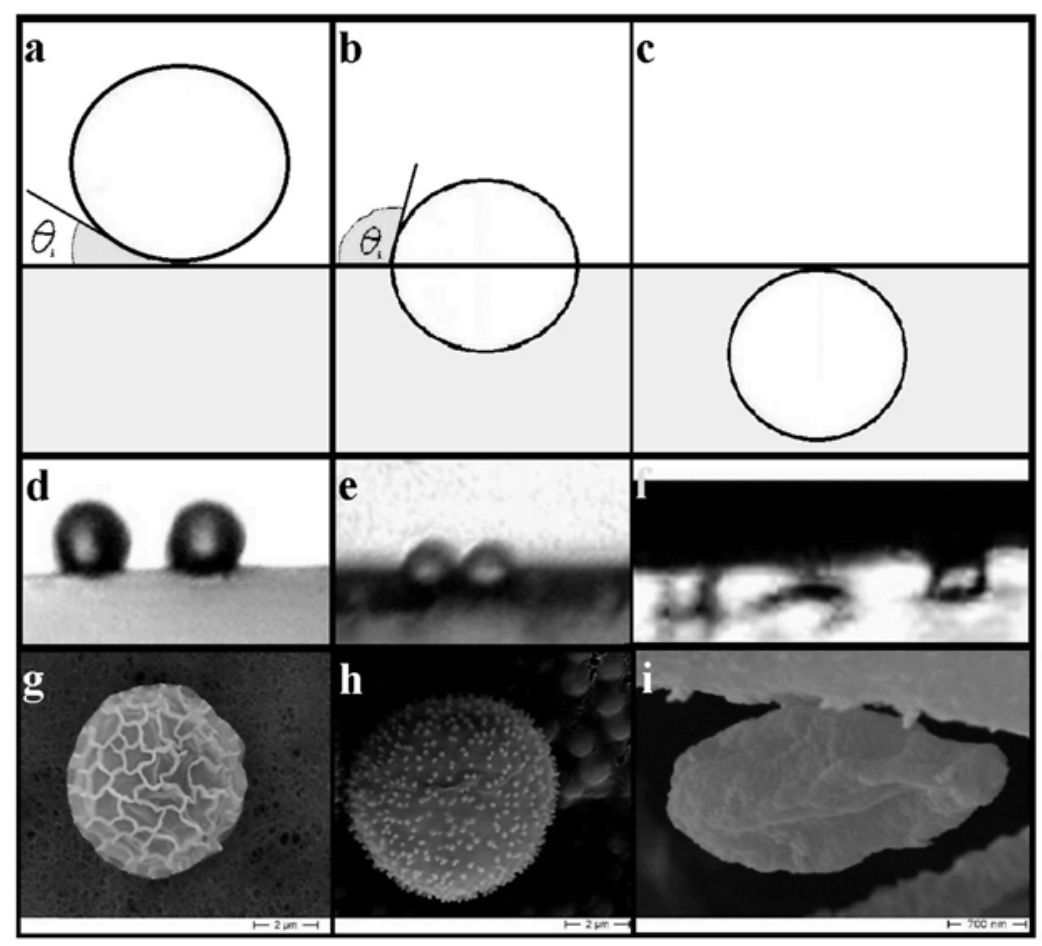

Fig. 3 - Overview of the three different groups of spore morphology. a) Spores with reticulate structure, b) Spores with spines and c) Spores with smooth surface. The top line shows the measured contact angle. The middle line shows a lateral picture $(\mathrm{d}-\mathrm{f})$. The last line shows an electron-microscopic image of a typical spore $(g-i)$.

After contact with water, reticulate spores showed a small contact area with the liquid medium. Spores with spiny surface seemed to be half sunk (Fig. 3). After documentation of these phenomena, the contact angle ( $\cos \theta_{\mathrm{w} / \mathrm{r})}$ was calculated. For spores with a reticulate surface, angles from $0.75^{\circ}$ to $0.99^{\circ}$ and for spores with a spiny surface, angles from $0.05^{\circ}$ to $0.97^{\circ}$ were computed (Tab. 1). 
Table 1 Measured contact angle $\left(\theta_{\mathrm{i}}\right)$ of the spores and the calculated energy $\sigma \mathrm{LS}$.

\begin{tabular}{|c|c|c|c|c|}
\hline Spore surface & Angle $\theta \mathbf{i}$ & $\operatorname{Cos} \theta w / \mathbf{r}$ & (n) & $\sigma \mathbf{L S}$ \\
\hline \multicolumn{5}{|l|}{ reticulate } \\
\hline Lycogala epidendrum & 54.47 & 0.748463545 & 18 & \\
\hline Trichia favoginea & 51.93 & 0.986518981 & 32 & \\
\hline Trichia decipiens & 67.1 & 0.885054222 & 19 & \\
\hline Stemonitis fusca & 102.78 & 0.793507788 & 36 & \\
\hline $\begin{array}{l}\text { Metatrichia floriformis } \\
\text { spiny }\end{array}$ & 38.91 & 0.758341643 & 36 & 25.61 \\
\hline Arcyria cinerea & $\begin{array}{c}61 \\
\text { under the water }\end{array}$ & 1 & 20 & \\
\hline Arcyria denudata & surface & & & \\
\hline Didymium nivicolum & 120.93 & 0.998900435 & 21 & \\
\hline Badhamia utricularis & $\begin{array}{c}120.83 \\
\text { under the water }\end{array}$ & 0.967804066 & 9 & \\
\hline Collaria arcyrionema & surface & & & \\
\hline \multicolumn{5}{|l|}{ Fuligo septica var. } \\
\hline candida & 112.3 & 0.496096621 & 10 & 50.81 \\
\hline Fuligo septica var. flava & 116.81 & 0.047223965 & 24 & \\
\hline Fuligo septica var. rufa & 120.32 & 0.57587552 & 10 & \\
\hline $\begin{array}{l}\text { Fuligo intermedia } \\
\text { smooth }\end{array}$ & 108.61 & 0.907545248 & 26 & \\
\hline Ceratiomyxa fruticulosa & $\begin{array}{l}\text { under the water } \\
\text { surface } \\
\text { under the water }\end{array}$ & & & 72.63 \\
\hline Licea parasitica & surface & & & 72.74 \\
\hline
\end{tabular}

Reticulate or spiny spores were treated with formic acid (20\%). For all spore types we observed sinking under the water meniscus (Fig 4c, f, i).

\section{Discussion}

We could show by comprehensive analyses of the spore surface that myxomycetes can be divided according to their spore surface into three major groups: smooth, reticulate and spiny surface. The calculated surface energy showed that the spores of the reticulate and spiny type do not sink into the water. A relation could be determined between the free surface energy $\sigma \mathrm{S}$ of a solid structure, the interface energy $\sigma \mathrm{LS}$ between the liquid phase and the spore located on it, the surface tension $\sigma \mathrm{L}$ of the liquid and the contact angle $\theta_{\mathrm{i}}$ between both.

Whether this quality was an advantage for this group of myxomycetes is unknown. If they are adhered to water after the first contact, a removing and dispersal to another locality by air is not possible. However, the spores are still mobile enough to be able to disperse and only after a certain time can they sink into the medium to germinate. We detected other structures on the top of the spore-ornamentation (Hoppe \& Kutschera 2011). These structures can be removed or modified by formic acid (Fig. 4c, f, i). This is accompanied by a loss of hydrophobicity. We hypothesize that these structures may be hydrophobines like those of fungi (Morris et al. 2010). We suppose that the effect of the hydrophobicity is caused by two different attributes: spore ornamentation and hydrophobines. On one hand, the surface structure has no essential effect on the surface-energy and the intensity of the repulsion is an effect of the hydrophobines. On the other hand, these structures which exist on the surfaces of all spore-ornaments (reticulate and spiny) are directly involved in the effect.

In arid areas or locations with fast changing environment conditions, the hydrophobic effect could be necessary for spore distribution. In humid areas, spores with reticulate structure can be taken up in the atmosphere to colonize a more suitable habitat. We believe that myxomycetes with smooth spores represent a prototype of spore morphology. The other groups (reticulate and spiny) have presumably developed independent of each other. In most genera only one surface type appears, but there are also some exceptions. For example, most species of the genus Fuligo show 
spiny spores. However, the species $F$. cinerea shows a reticulate surface. The early independent development of the order Physarales seems to have favoured spores with spine surface. Spinestructures on the spore surface are also to be found in other orders (Echinosteliales, Liceales, Stemonitales and Trichiales). The number of the spores with reticulate surface is still high within these orders (Fig. 5).
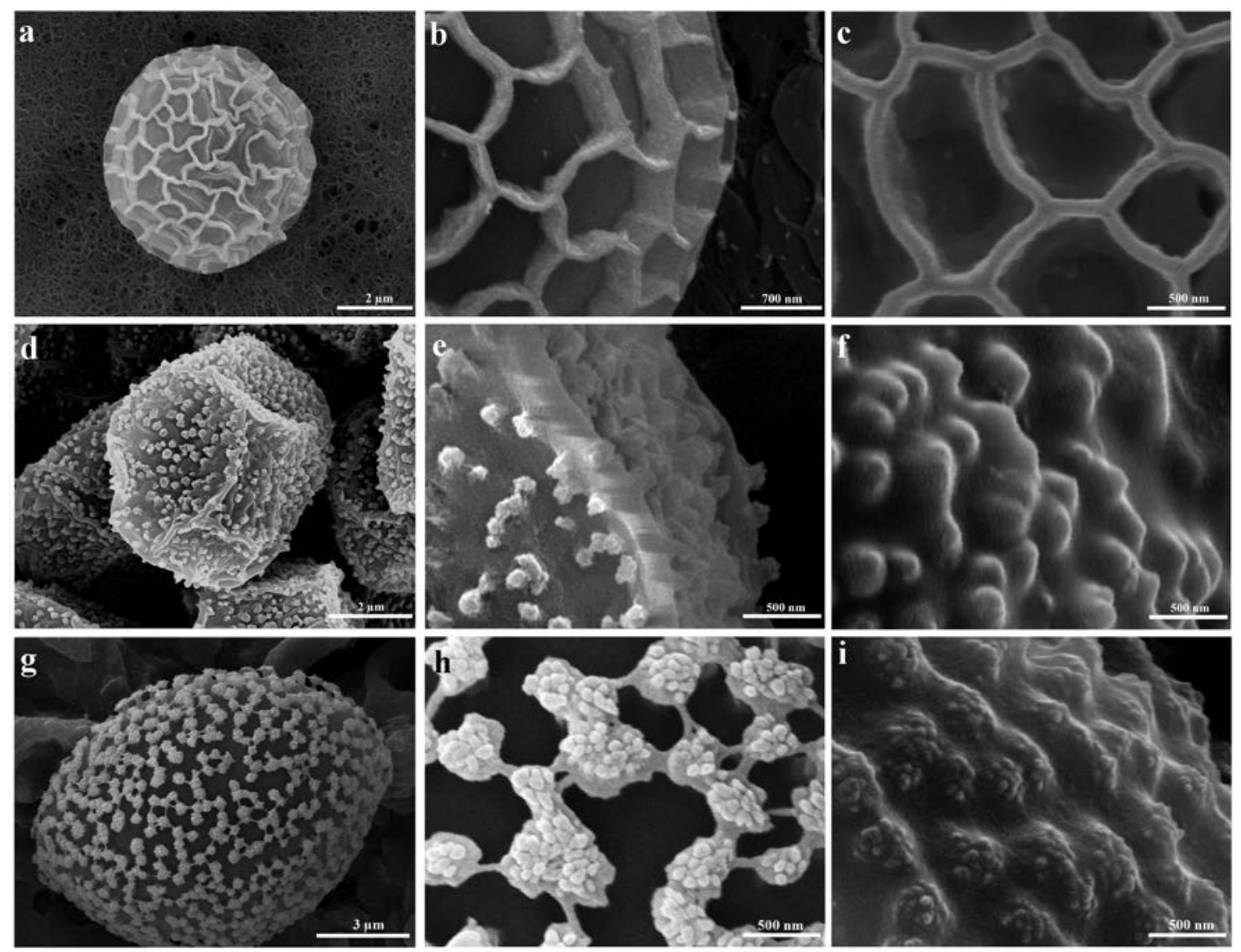

Fig. 4 - The spores of T. arachnoidea (a, b, c), F. septica (d, e, f) and M. floriformis (g, h, i). Pictures one and two of each line show the ordinary spore ornamentation. Pictures: $\mathrm{c}, \mathrm{f}$ and $\mathrm{i}$ show the spore ornamentation after incubation with formic acid for $10 \mathrm{~min}$.

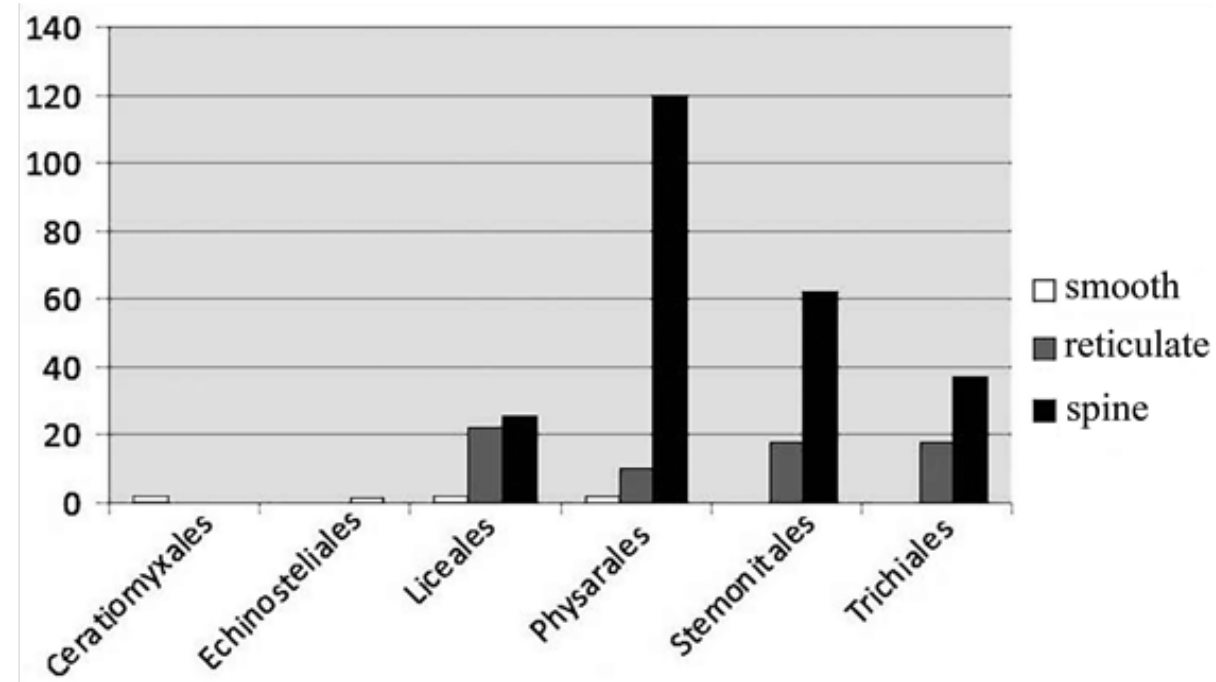

Fig. 5 - Statistics of the morphology of spore-surface on data of 320 myxomycetes-species. 
Surface structures of biological materials are functional and myxomycetes have three different spore surfaces. We hypothesized different evolutionary strategies of myxomycetes are based on the adaptation to different forms of dispersal. There are more than 900 species of myxomycetes (Lado 2001), but only few of them have been examined by SEM so far and further studies are needed.

\section{Acknowledgement}

We thank Dr. A. Feest (University of Bristol, United Kingdom) for helpful comments on an earlier version of the manuscript.

\section{References}

Bruck WF. 1907 - Beiträge zur Physiologie der Mycetozoen. Zeitschrift für allgemeine Physiologie. 7: 505-558.

Hoppe T, Kutschera U. 2010 - In the shadow of Darwin: Anton de Bary's origin of myxomycteology and a molecular phylogeny of the plasmodial slime molds. Theory Biosci. 129: 15-23.

Hoppe T, Kutschera U. 2011 - Plasmodiale Schleimpilze: Die kommunikativen zellulären Räuber unserer Wälder. IN: Kutschera U. (Ed.): Darwinia Nova - Verborgene Kunstformen der Natur. LIT-Verlag, Berlin, Münster, Wien, Zürich, London.

Kwon Y, Patankar N, Choi J, Lee J. 2009 - Design of surface hierarchy for extreme hydrophocity. Langmuir 25: 6129-6136.

Lado C. 2001 - Nomenmyx. A nomenclatural taxabase of myxomycetes. Cuad Trab Flora Micol Ibér 16: 1-221.

Noblin X, Yang S, Dumais J. 2009 - Surface tension propulsion of fungal spores. J. Exp. Biol. 212: 2835-2843.

Morris VK, Ren Q, Macindoe I, Kwan AH, Byyrne N, Sunde M. 2010 - Recruitment of class I hydrophobins to the air:water interface initiates a multi-step process of functional amyloid formation. J. Biol. Chem. 286: 15955-15963.

Müller H. 2006 - Assoziation von Coleoptera mit Myxomycetes in Thüringen. Entomologische Zeitschrift 116: 75-78.

Stephenson SL, Schnittler M, Novozhilov YK. 2008 - Myxomycete diversity and distribution from the fossil record to the present. Biodivers Conserv. 17:285-301.

Tesmer J, Schnittler M. 2007 - Sedimentation velocity of myxomycete spores. Mycol. Progress 6: 229-234.

Young T. 1805 - An Essay on the Cohesion of Fluids. Philosophical Transactions of the Royal Society of London 95: 65-87. 